\title{
Kendinden Kanatlı (Finli) Borulu Ekonomizerlerin Termal Performansa Etkisi
}

\author{
Ayşegül Balikci ${ }^{1 *}$, Berna Çeri ${ }^{2}$, Tarkan $\mathrm{Koca}^{3}$ \\ 1* Mimsan Endüstri Kazanları A.Ş., Malatya, Türkiye, (ORCID: 0000-0002-8136-4484), aysegulbalikciii @ gmail.com \\ 2 Mimsan Endüstri Kazanları A.Ş., Malatya, Türkiye (ORCID: 0000-0002-0454-6495), bernaceri@ @otmail.com \\ 3 İnönü Üniversitesi, Mühendislik Fakültesi, Makine Bölümü, Malatya, Türkiye (ORCID: 0000-0002-6881-4153), tarkankoca@inonu.edu.tr
}

(İlk Geliş Tarihi 30 Aralık 2021 ve Kabul Tarihi 31 Ocak 2022)

(DOI: 10.31590/ejosat.1051048)

ATIF/REFERENCE: Balikci, A., Çeri, B. \& Koca, T. (2022). Kendinden Kanatlı (Finli) Borulu Ekonomizerlerin Termal Performansa Etkisi. Avrupa Bilim ve Teknoloji Dergisi, (33), 400-406.

\section{$\ddot{O} \mathbf{z}$}

Enerji kaynaklarının çok önemli olduğu günümüzde enerji kaynaklarını yoğun kullanan sektörlerde baca gazının atık 1sı geri kazanımı için alternatif sistemler uygulanmaktadır. Uygulanan alternatif sistemleri ile ısı kayıpları minimum düzeye getirilmeye çalışılmaktadır. $\mathrm{Bu}$ çalışmada kendinden kanatlı (finli) borulu ekonomizer kullanılarak termal performans artırılmaya çalışılmıştır. Çalışma hem deneysel hem de nümerik olarak yapılarak karşılaştırılmıştır. Termal performansı ölçebilmek için deney seti kurulmuştur. Ayrıca 1sı transfer analizi için Solidworks Flow Simulation programı, performans ölçümü için FireCAD programı kullanılmıştır. Çalışmanın diğer çalışmalardan en önemli farkı, kanat aralık mesafeleri değiştirilerek farklı tip finli boruların kullanılmasıdır. Kanat aralıkları 5 , 10 ve $14 \mathrm{~mm}$ olarak belirlenmiştir. Kanat aralıklarına göre tüm borularda 1sı transferleri ve basınç düşümleri için hesaplamalar yapılmıştır. Ekonomizer performansına en iyi etki de bulunan fin aralığı teorik ve deneysel olarak incelenip gözlenmiştir. Yapılan analizler sonucunda elde edilen çıktılar tablo ve şekil halinde verilmiştir.

Anahtar Kelimeler: Isı Değiştiriciler, Ekonomizer, Isı Transferi.

\section{Impact of Self-Winged (Finnish) Tubular Economizers on Thermal Performance}

\begin{abstract}
Today, where energy sources are very important, alternative systems are applied for waste heat recovery of flue gas in sectors that use energy resources intensively. With the alternative systems applied, heat losses are tried to be minimized. In this study, thermal performance was tried to be improved by using self-winged (finnish) tubular economy. The study was compared both experimentally and numerically. An experimental set has been set up to measure thermal performance. Solidworks Flow Simulation program for heat transfer analysis and FireCAD program for performance measurement were also used. The most important difference of the study from other studies is the use of different types of fin pipes by changing the wing range distances. The wingspans are 5,10 and 14 mm. Calculations were made for heat transfers and pressure drop in all pipes according to wing ranges. The finnish range, which also has the best effect on economic performance, has been examined and observed theoretically and experimentally. The results obtained as a result of the analyses are given in tables and figures.
\end{abstract}

Keywords: Heat Exchanger, Economizers, Heat Transfer.

\footnotetext{
*Sorumlu Yazar: aysegulbalikciii@gmail.com
} 


\section{Giriş}

Isı değiştiricileri farklı sıcaklıklardaki iki akışkan arasındaki 1S1 aktarımını sağlayan 1sıl cihazlardır. Isı değiştiricileri güç üretimi, taşıt araçları, 1sı depolamasında, üretim endüstrisi, elektronik, gıda ve kimya sanayi, proses, çevre mühendisliği, iklimlendirme, enerji üretimi, atık ısının geri kazanılması, soğutma ve uzay uygulamaları gibi çok geniş kullanım alanlarına sahiptir. Isı değiştiricileri 1sı geçiş şekli, konstrüksiyon yapıs1, 1S1 geçiş mekanizması, akış düzeni, akış türü, akış sayısı gibi kriterlere göre sınıflandırılmaktadır. Isı transfer miktarı ve basınç düşüm değerleri isı değiştiricileri tasarımında oldukça önemlidir. Yüksek 1sı üretimi ve tüketimi olan bir çok endüstriyel tesislerde dışarıya atılan yüksek miktarda 1sı enerji ortaya çıkar. Bu isıdan faydalanabilmek için bir çok isletmede atık sıcak sıvı ve gaz akışkanlardan 1sı geri kazanım uygulamaları yapılmaktadır. Farklı ısı geri kazanım teknikleri ile enerji kayb1 geri kazanılabilmektedir. Kazanlılan bu enerji ile genellikle taze hava ortama gönderilmeden önce belirlenen sıcaklık değerine göre 1sıtılır ya da soğutulur. Isı geri kazanımın uygulamalarında temel olarak uygulama, düşük sıcaklıklı ortamlarda taze havanın 1sıtıcı bataryaya ulaşmadan önce biraz 1sıtılması veya yüksek sicaklıklı ortamlarda taze havanın soğutucu bataryaya ulaşmadan önce biraz 1sıtılması şeklindedir. Dış hava ve iç hava arasındaki farkların daha fazla olduğu yer ve zamanlarda daha fazla kazanç elde edilir.

Ekonomizerler, kazandan gelen atık baca gazının isısından faydalanarak kazan besleme sistemi ile akışkanı 1sıtan 1S1 değiştiricilerdir. Ekonomizerler, kazanlardan bacaya verilen gazlar üzerinde bulunan ısının bir kısmını sirküle ederek suya aktarılmasını sağlar ve böylece geri kazanım elde etmiş olur. Ekonomizerler buhar kazanları, kızgın yağ kazanları, sıcak ve kızgın su kazanları gibi sistemlerde besleme yolu ile akışkanı ısıtarak kazan verimliğini artırarak yakıt tasarrufu sağlamaktadırlar. Besleme yolu ile kazanılan 1s1, tesislerin kullanım amacına göre 1sıtma ve sıcak su ihtiyaçlarında kullanılmaktadır. Ekonomizerler duman borulu ve su borulu olan tiplerde üretilmektedir. Duman borulu ekonomizerlerde, duman gazı, boru içinden akarak 1sı transfer miktarını düşürür. Bu durum da kapladıkları hacim fazla olup buna bağlı olarak boruda delinmeler erken oluşur. Ekonomizer de 1sı transfer yüzey alanını ve ısı aktarım hızını en yüksek seviyeye çıkarmak için metalik kanatlarla kaplı borular kullanılmaktadır. Ekonomizerler tip ve yap1 özelliklerine göre düz veya firkete borulu, kanatlı borulu ve helezon ve spiral Borulu ekonomizerler olarak sinıflandırılırlar. Düz veya firkete borulu ekonomizerler; kömür, fuel oil vb. yakitlardan elde edilen kirli duman gazlarından 1s1 geri kazanımı elde ederler. Kanatlı borulu ekonomizerler ise doğal gaz, LPG vb. yakıtlardan elde edilen temiz duman gazları ve sıcak havayı 1sı geri kazanımı elde etmek amaçlı kullanırlar. Helezon ve spiral borulu ekonomizerler; duman gazlarının kirlilik durumlarından etkilenmeyen yapıda olduklarından her türlü atık gazlarda kullanılırlar. Isıtma yüzeyi için kullanılan boruların çapı 1 " ve 2 " aralığındaki dikişli veya dikişsiz borulardan seçilebilirler. Doğru malzeme kullanımı uygulama şartlarına göre önem taşımaktadır. Boru dizilimleri kare veya şaşırtmalı olabilir. Şaşırtmalı dizilim ısı transfer miktarına göre daha iyi basınç düşümü sağlar. Doğalgaz gibi temiz yakıtlarda da tercih sebebi olmaktadırlar. Kare diziliş partikülü fazla olan uygulamalarda kullanımı tercih edilir.
Sıv1-gaz akışkanlı 1Sı değiştirilerde ekonomizerler havayı ısıtma veya soğutma işleminde kullanılırlar. Borunun iç kısmından sıvı akışkanın geçişi sağlanırken, dış kısmından gaz akışı sağlanmaktadır. Bundan dolayı kanatlar borunun dış kısmına yerleştirilir. Isı transferindeki düşüşe bağlı olarak borunun hem dış kısmına hem de iç kısmına kanatların yerleşimi sağlanır. Boru içine kanatlar genelde evaparatör ve kondenserler de yerleştirilir. Boru üzerine kanat yerleşimi lehim, kaynak, sıkı geçme veya sarma tutturma işlemleri ile gerçekleştirilir. Boru ve kanat malzemesine göre 1s1 değiştiricilerin kullanım sicaklığı bu tutturma işlemlerine bağlıdır. Tokgöz ve arkadaşları (2019), bu çalışmada doğalgaz yakıtlı bir kazanda baca gazındaki 1sı geri kazanım performansını araştırmışlardır. Baca gazındaki ısıdan faydalanmak için reküperatör tasarlamışlardır. Yapılan analizler sonucunda sistemin 15 yıllık ekonomik ömrü için toplam yakıt tasarrufu miktarını belirtmişlerdir. Uysal (2019), bu çalışmada otomotiv fabrikasında atık 1sıdan yararlanarak verimliliği artırmak amacıyla ekonomizer tasarlanmıştır. Elde edilen verileri değerlendirmiş ve sonuç olarak tesisin doğalgaz tüketiminin \% 10-12 oranında azalacağını ve geri ödeme süresinin de 2,76 yıl olacağını belirtmiştir. Hüseyin (2013), bu çalışmada sanayide enerjiyi verimli kullanabilmek adına atık 1sı geri kazanımı çalışması yapmıştır. Ray ve profil haddehanesi tav firınında ekonomizer ile atık ısı kazanım çalışması yapılmıştır. Çalışmada baca gazı ölçümleri yapılmış ve ekonomizer verimi \%84 olarak tespit etmiştir.

Yapılan bu çalışma da 1Sı değiştirici modellemesi için çeşitli geometriler tasarlanmıştır. Isı değiştiricisi finli boru tipi için belirlenen toplam üç farklı geometride, en etkin ve verimli 1s1 değiştirici tipinin belirlenebilmesi için Solidworks programında Simülasyon Analiz ve FireCAD programı ile termal tasarım ve performans hesaplamaları yapılmıştır. Ayrıca deneysel olarak da çalışılmış ve değerler karşılaştırılmıştır.

\section{Materyal ve Metot}

Yapılan bu çalışmada finli borulu ekonomizerin 1sı transferi ve basınç kaybına etkisi araştırılmıştır. Finli boru ana elemanları iki boru ve levhalardan oluşmaktadır. Boru çapı Ø42.4 mm’den olup borunun uzunluğu 1 metredir. Boruya bağlı olan kanat levhalarının uzunluğu $196 \mathrm{~mm}$ olup et kalınlıkları $1.5 \mathrm{~mm}$ 'dir. Borunun dış kısmına yerleştirilen kanat levhaları gaz ark kaynağ ${ }_{1}$ ile birleştirilmiştir. Boru iç kısmına giren suyun sıcaklığı $132{ }^{\circ} \mathrm{C}$, hızı $5 \mathrm{~m} / \mathrm{s}$ ve basıncı 10 bar'dır. Borunun dış kısmından geçen kanatlara etki eden gazın giriş sıcaklığ $205^{\circ} \mathrm{C}$ 'dir. Kanat aralıkları $5 \mathrm{~mm}, 10 \mathrm{~mm}, 14 \mathrm{~mm}$ 'den oluşan kanatçıklar Ø42.4 mm çaptaki 1 metrelik boruya dizilimi yapılarak analiz değerlendirilmesi yapılmıştır. Endüstriyel tesislerde ekonomizerlerin çalışma prensibi tesislerin üretim gücünü göre değişmektedir. Atık 1Sı kazanlar ile enerji geri kazanımı ortaya çıkmakta ve üretim düşürülmeden ihtiyaç duyulan enerjinin azaltılması sağlanmaktadır. Yapılan çalışmada ekonomizer atık 1S1 kazanı ön 1sıtıcı işleminde kullanılmaktadır. Şekil 1' de görüldüğü gibi atık 1sı kazanı çalışma prensibine göre sisteme giren atık gaz, kül tutucu bariyerlerden geçerek süperheater olarak adlandırılan yüksek basınçlı kızdırıcıda buhar çevriminin arttırılmasını sağlar. Kızdırıcılardan çıkan gaz evaporatöre ulaşır ve soğutma işlemi gerçekleştirilir. Evaporatörde soğutma işlemi uygulanan gaz, ekonomizere geçiş yapar ve ısıyı geri kazanım sağlattırarak düşük basınçlı kızdırıcıya gönderilir. Kızdırıcı sonrası elde edilen buhar sisteme verilerek verimliliğin arttırılması sağlanır. 


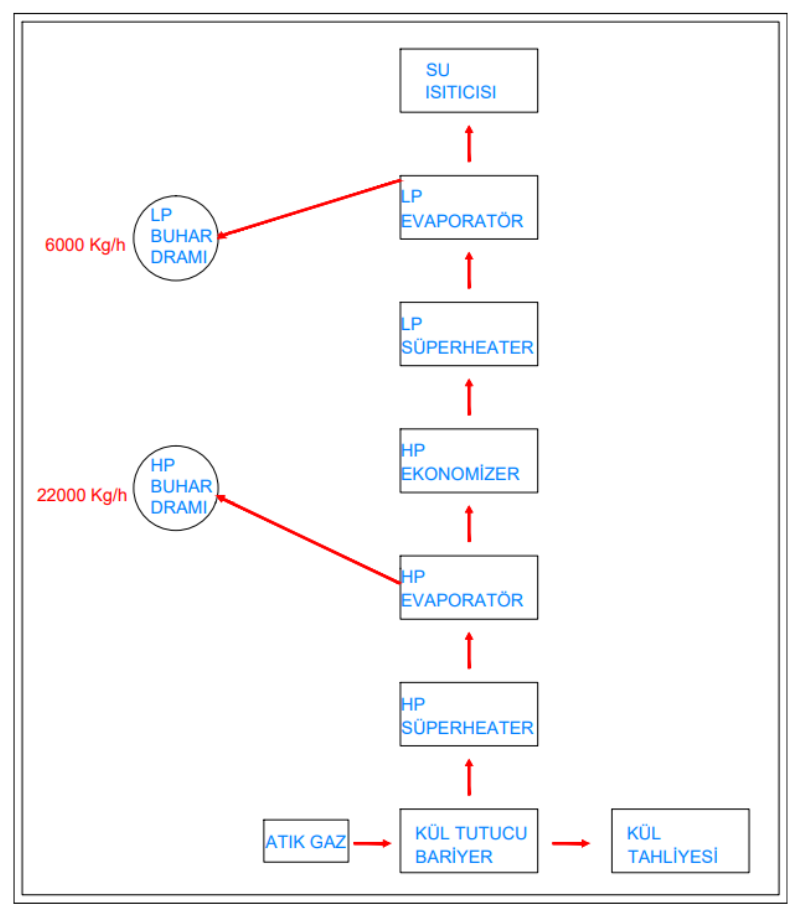

Şekil 1. Atık Isı Kazanı İş Akış Şeması (Figure 1. Waste Heat Boiler Workflow Chart)

Kendinden kanatlı finli borunun ekonomizer içerisindeki boru kanat montaj görünümü Şekil 2.'de verilmiştir.

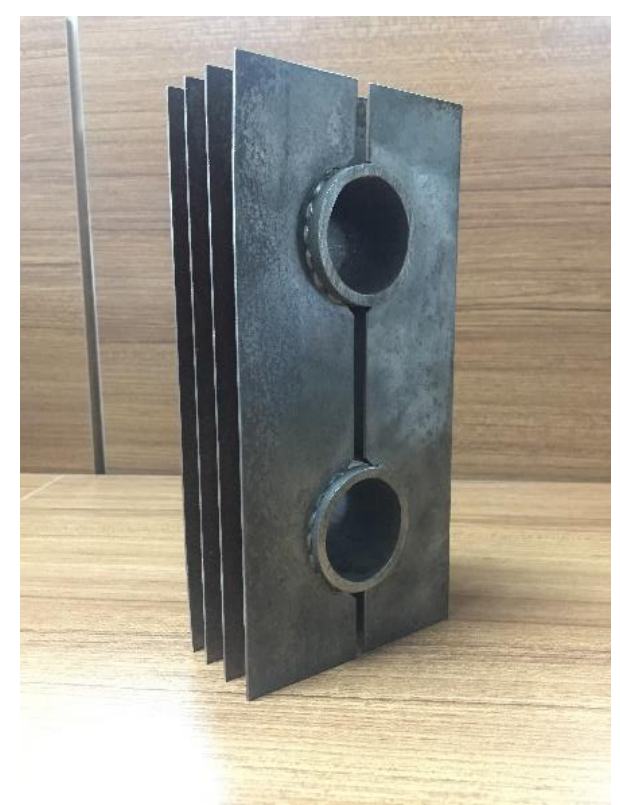

Şekil 2. Kendinden Kanatlı (Finli) Borulu Ekonomizer (Figure 2. Self-Winged (Finnish) Tubular Economist)

$\mathrm{Bu}$ çalışmada atık 1Sı kazanına bağlı ekonomizer tipi 1Sı değiştiricisi tasarımı yapılmıştır. Akışkanların giriş, çıkış sıcaklıkları ve kütlesel debileri bilinmesi durumunda adım adım hesaplamaları yapılmıştır.

- Logaritmik sicaklık farkı bulunur.

$\Delta T_{m}=\frac{\Delta T_{1}-\Delta T_{2}}{\ln \left(\frac{\Delta T_{1}}{\Delta T_{2}}\right)}$
$\Delta T_{1}=T_{1 g}-T_{2 \mathrm{c}}$

$\Delta T_{2}=T_{1 c ̧}-T_{2 g}$

- Boru ve gövde tarafı debiler için 1sı yükü hesaplanır.

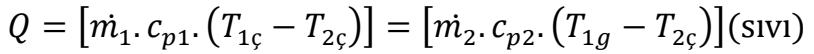

$\mathrm{Q}=\dot{m} \cdot h_{s b}$ (buhar)

- Boru tarafı için ısı taşınım katsayısı hesaplanır.

Reynolds sayıs1, $\operatorname{Re}=\frac{V \cdot d_{i c}}{v}$

Prandtl sayıs $\operatorname{Pr}=\frac{v}{a}$

Nusselts sayısı $\mathrm{Nu}=\frac{h_{i} \cdot d_{i c ̧}}{k}$

- Isı değiştiricisi toplam yüzey alanı, n bir geçişteki toplam boru sayıs1,

$Q=\Delta T_{m} \cdot A \cdot K_{D}$

- Isı değiştiricisi boru uzunluğu,

$L=\frac{\mathrm{A}}{d_{i c} \cdot \pi \cdot n}$

- $\quad$ Boru içindeki basınç düşümü, V boru içindeki akışkan hızı $\mathrm{m} / \mathrm{s}$,

$$
\Delta \mathrm{P}=\frac{L \cdot f_{l}}{d_{i c}} \rho \frac{V^{2}}{2}
$$

Hesaplamaları yapılmıştır.

Yapılan hesaplamalar doğrultusunda atık 1S1 kazanın tasarımı belirlenerek 3 boyutlu görünümü Solidworks programında çizilmiştir. Kazanın ön ve kesit görünümü Şekil 3.' te verilmiştir.
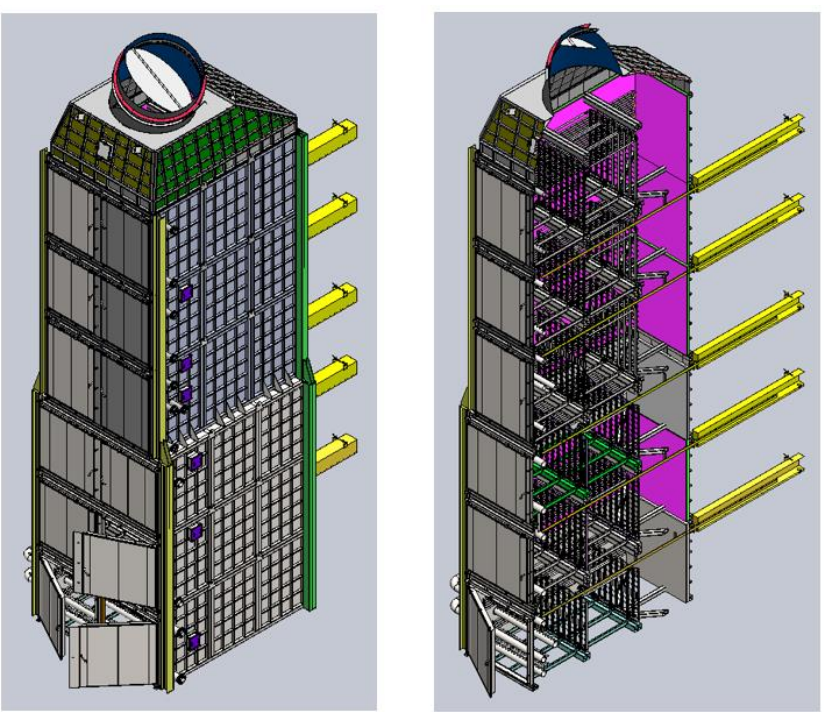

Şekil 3. Atık Isı Kazanının 3 Boyutlu Ön ve Kesit Görünümleri (Figure 3. 3D Front and Section Views of Waste Heat Boiler)

Atık 1S1 kazanın 3 boyut görünümü sonrasında projelendirme yapılarak 2 boyutlu görünümü hazırlanmıştır. 2 boyutlu projeye göre atık 1sı kazanının işletmede yerleşimi Şekil 4.’te verilmiştir. 


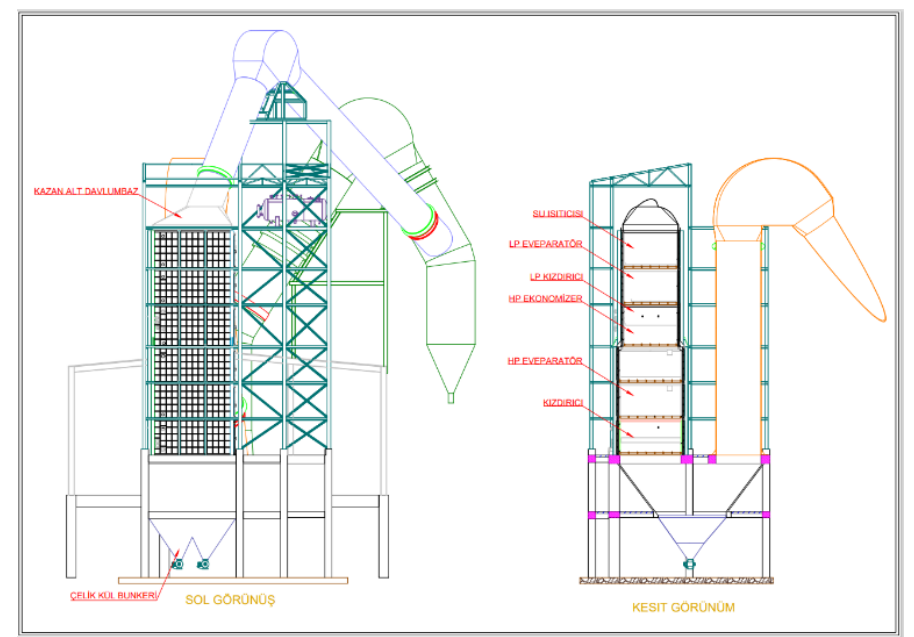

Şekil 4. Atık Isı Kazanı 2 Boyutlu Sistem Şeması Sol ve Kesit Görünümü (Figure 4. Waste Heat Boiler 2D System Diagram Left and Cross Section View)

$\mathrm{Bu}$ çalışma kapsamında atık 1sı kazanında yer alan ekonomizere bağlı kendinden kanatlı finli borunun kanat aralığ teorik olarak hesaplanmıştır. İşletme olarak Nuh Çimento'ya ait atık 1S1 kazanında bulunan ekonomizerin performansı incelenmiştir. Atık 1Sı kazanının dış görünümü Şekil 5.'te verilmiştir.

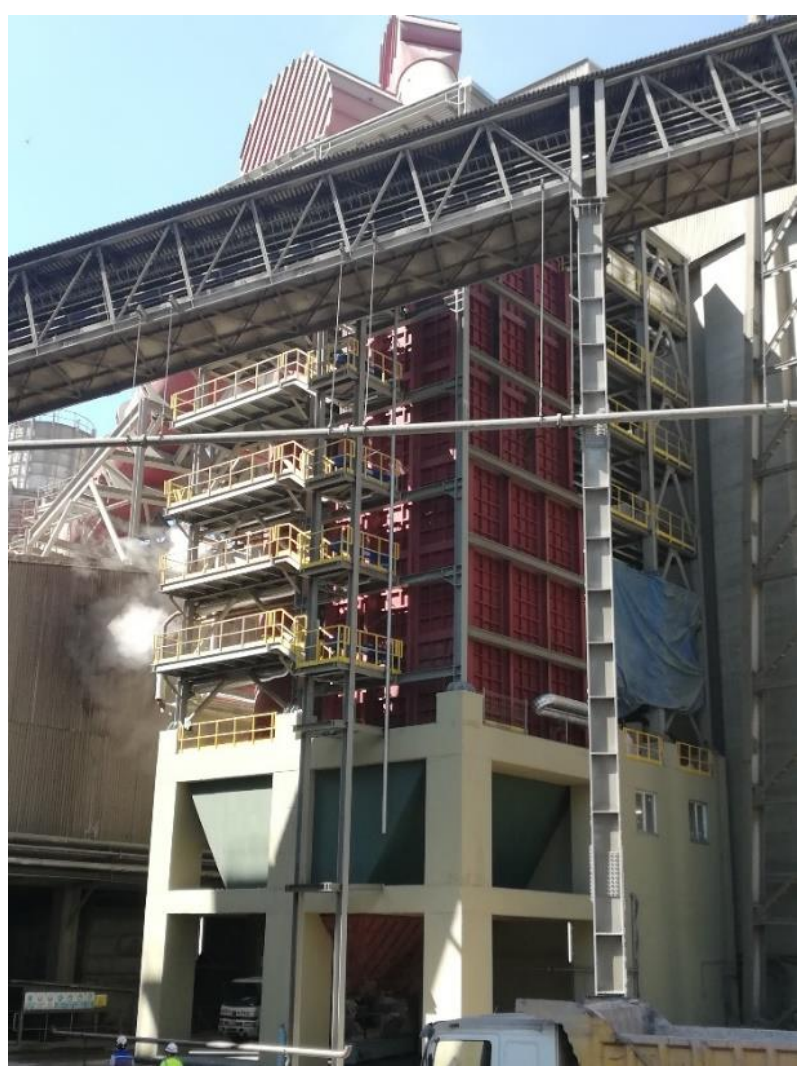

Şekil 5. Atık Isı Kazanı Tesis Görünümü (Figure 5.Waste Heat Boiler Plant View)

\section{Araştırma Sonuçları ve Tartışma}

Yapılan analiz çalışmasına bağlı olarak 1sı değiştiricilerin tasarımda en önemli parametreleri 1sı transfer performansı ve basınç kaybıdır. Çalışmada 3 farklı kanat aralığında kendinden kanatlı finli borulu ekonomizer imal edilmiş olup, her biri için analizler yapılmıştır. Yapılan analizlerde sabit olan parametreler; su için giriş sıcaklığ $132^{\circ} \mathrm{C}$, basıncı $10 \mathrm{bar}$, hızı $5 \mathrm{~m} / \mathrm{s}$ ve gaz için giriş sıcaklığ $205^{\circ} \mathrm{C}, \quad$ hızı $0,8 \quad \mathrm{~m} / \mathrm{s}$ 'dir. Değişken parametreler ise boruya montajı yapılan kanat aralığıdır. Isı transfer ve hız ölçüm için kullanılan FireCAD programı ile 1sıl performans değerlendirilmesi yapılmıştır. Çalışma sonucunda analiz modelleme işlemi Solidworks Flow Simülasyon programında gerçekleştirilmiştir. Finli borunun ekonomizerdeki yerleşimi Şekil 6'da kesit görünüm halinde verilmiştir

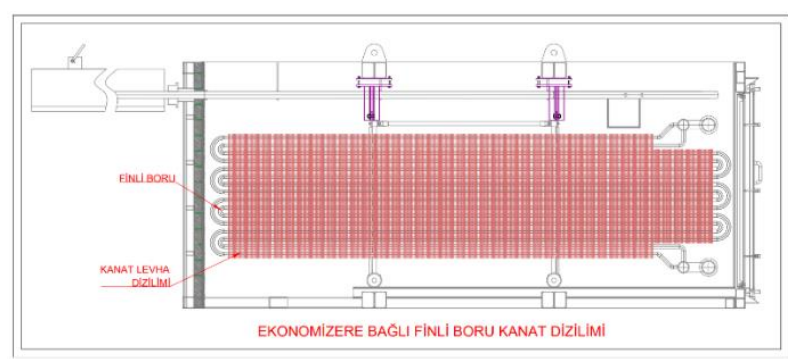

Şekil 6. Kendinden Kanatlı (Finli) Boru'nun Ekonomizerdeki Yerleşim Görünümü (Figure 5. View of Self-Winged (Finnish) Pipe in Economy)

1 metre uzunluğundaki finli borunun çapı Ø42.4 mm, kanat dizilim aralığ $5 \mathrm{~m}$, kanat levha sayısı 154 adet, kanat levha et kalınlığı $1.5 \mathrm{~mm}$ ve kanat levhanın uzunluğu $196 \mathrm{~mm}$ olup analiz sonuçları Şekil 7' de verilmiştir.

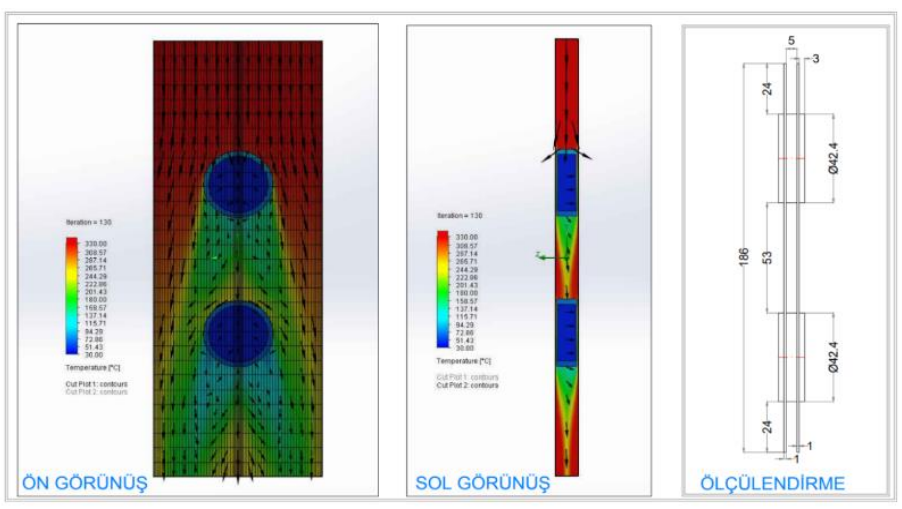

Şekil 7. Finli Boru Kanat Aralığı 5 mm (Figure 7. Finned Pipe Wing Range $5 \mathrm{~mm}$ )

Finli borunun kanat aralığının 5 mm ve kanat sayısının 154 adet olarak alındığı ekonomizer için FireCAD programında sabit parametre değerleri programa girilerek performans değerleri hesaplanmıştır. Şekil 8'de performans analiz sonuçları görülmektedir.

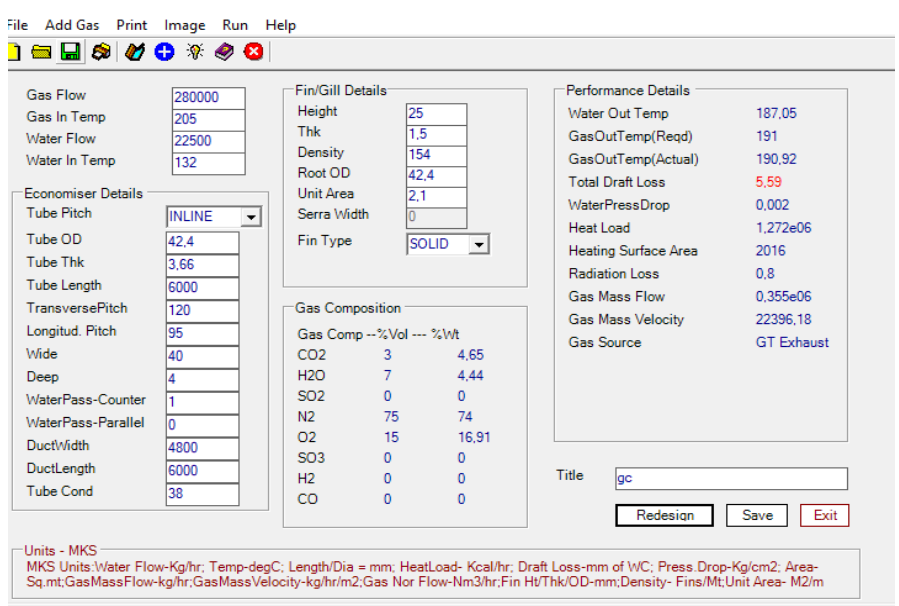

Şekil 8. FireCAD Program Ekonomizer Performans Etkisi-1 (Figure 8. Program Economy Performance Impact-1) 
Hesaplama sonuçlarına göre basınç kaybı $4.62 \mathrm{mmSS}$, 1sıtma yüzey alanı $1560 \mathrm{~m}^{2}$, gaz çıkış sıcaklığı $191^{\circ} \mathrm{C}$ ve su çıkış sıcaklığ $187^{\circ} \mathrm{C}$ olarak bulunmuştur.

1 metre uzunluğundaki finli borunun çapı Ø42.4 mm, kanat dizilim aralığı $10 \mathrm{~m}$, kanat levha sayısı 87 adet, kanat levha et kalınlığ $1.5 \mathrm{~mm}$ ve kanat levhanın uzunluğu $196 \mathrm{~mm}$ olup, analiz sonuçları Şekil 9' da verilmiştir.

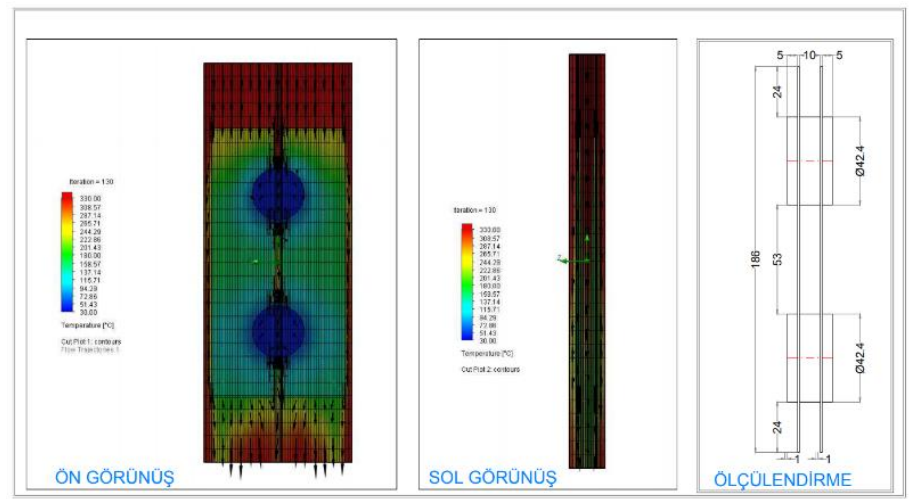

Şekil 9. Finli Boru Kanat Aralığı 10 mm (Figure 9. Finned Pipe Wing Range $10 \mathrm{~mm}$ )

Finli borunun kanat aralığının $10 \mathrm{~mm}$ ve kanat sayısının 154 adet olarak alındığı ekonomizer için FireCAD programında sabit parametre değerleri programa girilerek performans değerleri hesaplanmıştır. Şekil 10'da analiz sonuçları görülmektedir.

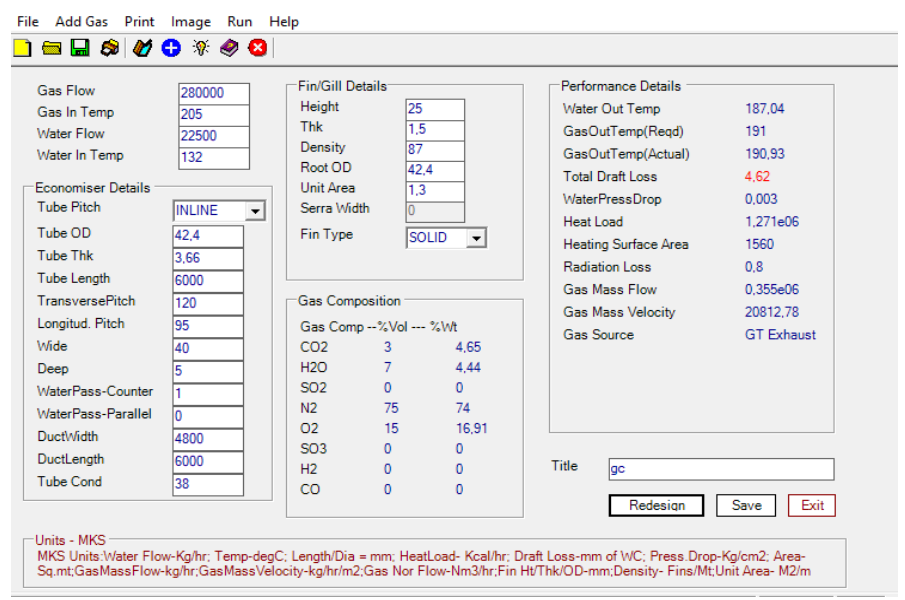

Şekil 10. FireCAD Program Ekonomizer Performans Etkisi-2 (Figure 10. Program Economy Performance Impact-2)

Hesaplama sonuçlarına göre basınç kaybı $4.62 \mathrm{mmSS}$, 1sıtma yüzey alanı $1560 \mathrm{~m}^{2}$, gaz çıkış sıcaklığg $191^{\circ} \mathrm{C}$ ve su çıkış sicaklığ $187^{\circ} \mathrm{C}$ olarak bulunmuştur.

1 metre uzunluğundaki finli borunun çap1 $\varnothing 42.4 \mathrm{~mm}$, kanat dizilim aralığı $14 \mathrm{~m}$, kanat levha sayısı 87 adet, kanat levha et kalınlığı $1.5 \mathrm{~mm}$ ve kanat levhanın uzunluğu $196 \mathrm{~mm}$ olan analizi Şekil 11' de verilmiştir.

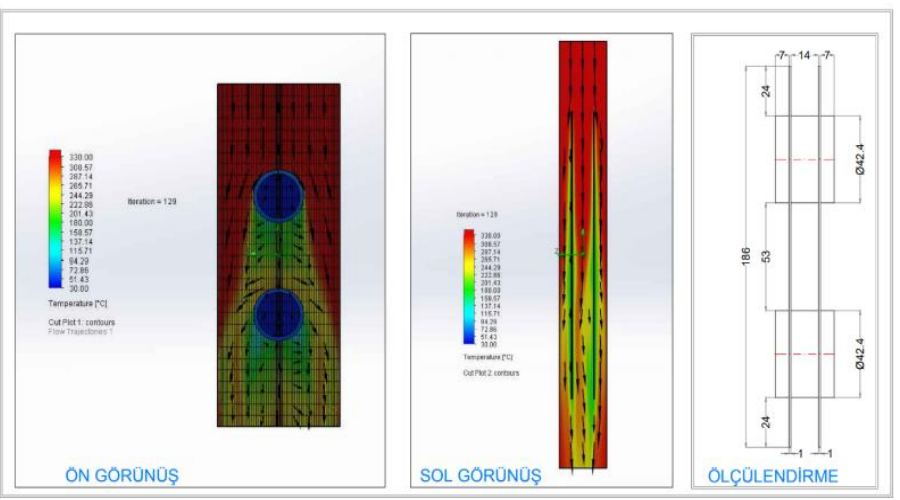

Şekil 11. Finli Boru Kanat Aralığı 14 mm (Figure 7. Finned Pipe Wing Range $14 \mathrm{~mm}$ )

Finli borunun kanat aralığının $14 \mathrm{~mm}$ olarak alındığ ekonomizer için FireCAD programında sabit parametreler girilerek performans değerleri hesaplanmıştır. Şekil 12'de analiz sonuçları görülmektedir.

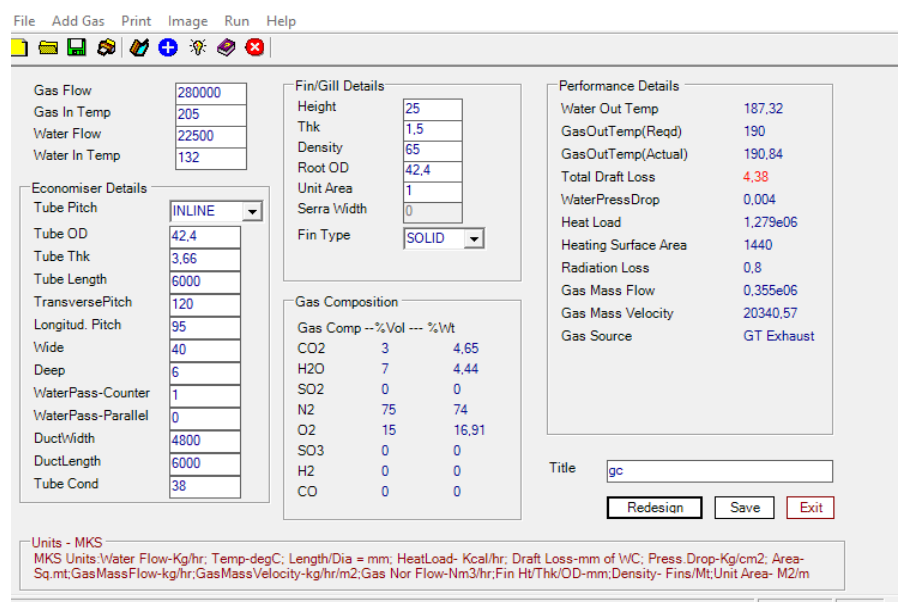

Şekil 12. FireCAD Program Ekonomizer Performans Etkisi-3

(Figure 11. Program Economy Performance Impact-3)

Firecad Programı ile su akışı (water flow) ve gaz akışı (gas flow) değerleri girilerek performans değerleri ve baca gazından çıkacak olan emisyon değerleri hesaplanmaktadır. Hesaplama sonuçlarına göre basınç kaybı $4.38 \mathrm{mmSS}$, ısıtma yüzey alanı $1440 \mathrm{~m}^{2}$, gaz çıkış sıcaklığ $190^{\circ} \mathrm{C}$ ve su çıkış sıcaklığ $187^{\circ} \mathrm{C}$ olarak bulunmuştur.

Veriler sonucunda 5, 10 ve $14 \mathrm{~mm}$ kanat aralığına göre basınç fark grafiği Şekil 13'te verilmiştir.

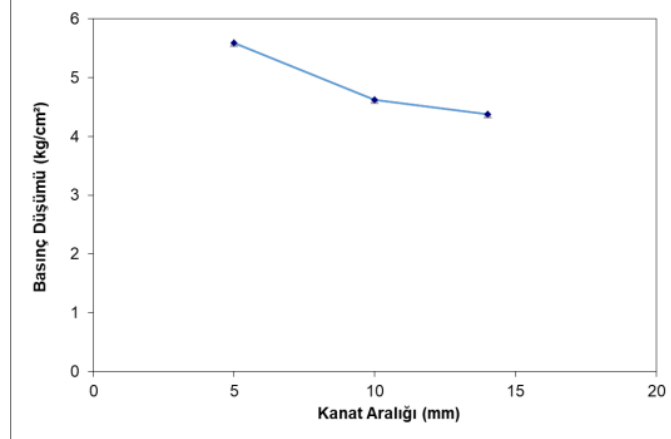

Şekil 13. Basınç Fark Grafiği (Figure 13. Pressure Difference Chart) 
Veriler sonucunda 5, 10 ve $14 \mathrm{~mm}$ kanat aralığına göre 1S1 transfer yüzey alanı grafiği Şekil 14' de verilmiştir.

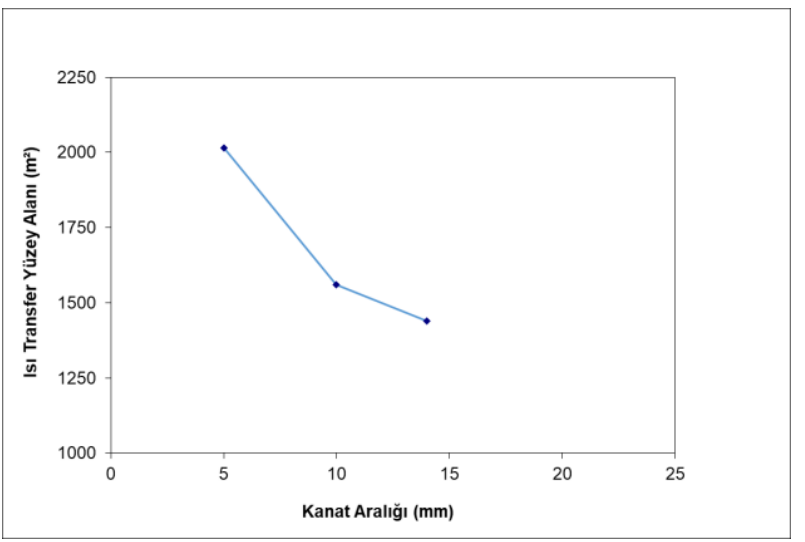

Şekil 14. Isı Transfer Yüzey Alanı (Figure 14. Heat Transfer Surface Area)

Elde edilen teorik veriler sonucunda işletme de kanat aralığı $5 \mathrm{~mm}$ finli boru kullanılmıştır. İşletme sonucunda elde edilen veriler Şekil 15 'te verilmiştir.

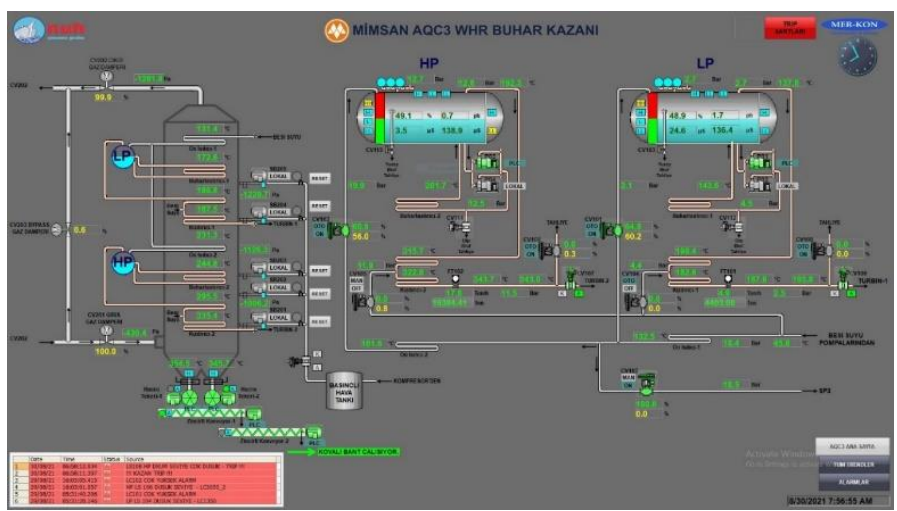

Şekil 15. Atık Isı Kazanı Tesis Otomasyon Değerleri (Figure 15. Waste Heat Boiler Plant Automation Values)

$\mathrm{Bu}$ sonuçlardan elde edilen otomasyon değerlerine göre ekonomizer besi suyu çıkış sıcaklığ $187.5^{\circ} \mathrm{C}$, basınç kaybı 38,4 $\mathrm{Pa}$ olarak verilmiştir. $5 \mathrm{~mm}$ kanat aralığındaki basınç kaybı teorik olarak $19 \mathrm{~Pa}$ elde edilmiştir. $10 \mathrm{~mm}$ kanat aralığındaki basınç kaybı teorik olarak $15 \mathrm{~Pa}$ elde edilmiştir. $14 \mathrm{~mm}$ kanat aralığındaki basınç kaybı teorik olarak $14 \mathrm{~Pa}$ elde edilmiştir.

Yapılan Solidworks Flow Simation analizi ve FireCAD ekonomizer performans ölçüm programı sonucunda ;

- Basınç kaybı farkı kanat levhanın aralığı 14 mm olan finli boruda $4.38 \mathrm{mmSS}$, kanat levhanın aralığı $10 \mathrm{~mm}$ finli boruda $4.62 \mathrm{mmSS}$ ve kanat levhanın aralığı 5 mm finli boruda $5.59 \mathrm{mmSS}$ olmuştur.

- Aynı sıcaklığa sahip gaz ve su akışkanlarında farklı 1sı transferi yüzey alanları elde edilmiştir. Fin Kanat levha aralığ 14 mm'de ısı transfer yüzey alanı $1440 \mathrm{~m}^{2}$, kanat levha aralığ $10 \mathrm{~mm}$ 'de 1 sı transfer yüzey alanı $1560 \mathrm{~m}^{2}$ ve kanat levha aralığ 5 mm'de $1 \mathrm{~s} 1$ transfer yüzey alanı $2016 \mathrm{~m}^{2}$ olmuştur.

- Baca gazından çıkan gazın sıcaklığı da $14 \mathrm{~mm}$ 'de $190.84^{\circ} \mathrm{C}, 10 \mathrm{~mm}^{\prime} \mathrm{de} 190.93^{\circ} \mathrm{C}$ ve $5 \mathrm{~mm}$ ' de $190.92^{\circ} \mathrm{C}$ çıkmıştır.

Çalışma sonucunda performans ölçüm değerleri Tablo 1'de verilmiştir.
Tablo 1. Performans ölçüm değerleri (Table 1.Performance measurement values)

\begin{tabular}{|l|l|l|l|}
\hline $\begin{array}{l}\text { Kanat } \\
\text { Aralı̆̆ı }\end{array}$ & $\begin{array}{l}\text { Basıç Kaybı } \\
(\mathbf{m m S S})\end{array}$ & $\begin{array}{l}\text { Isı Transfer } \\
\text { Yüzey Alanı } \\
\left(\mathbf{m}^{2}\right)\end{array}$ & $\begin{array}{l}\text { Baca Gazı } \\
\text { Çıkış Sıcaklığı } \\
\left({ }^{\circ} \mathbf{C}\right)\end{array}$ \\
\hline $5 \mathrm{~mm}$ & $5.59 \mathrm{mmSS}$ & $2016 \mathrm{~m}^{2}$ & $190.92^{\circ} \mathrm{C}$ \\
\hline $10 \mathrm{~mm}$ & $4.62 \mathrm{mmSS}$ & $1560 \mathrm{~m}^{2}$ & $190.93{ }^{\circ} \mathrm{C}$ \\
\hline $14 \mathrm{~mm}$ & $4.38 \mathrm{mmSS}$ & $1440 \mathrm{~m}^{2}$ & $190.84^{\circ} \mathrm{C}$ \\
\hline
\end{tabular}

\section{Sonuç}

$\mathrm{Bu}$ çalışmanın amacı işletmelerde ihtiyaç duyulan buharı atık ısı kazanı sayesinde verimli bir şekilde elde ederek sisteme gönderimi sağlamaktır. Ekonomizerin içerisinde bulunan kanatlı boruların belirli aralıklarla dizilimi sağlanarak et kalınlıklarında konfigürasyon oluşturulmuştur. Kanatlı borularda 3 farklı konfigürasyon oluşturularak FireCAD ve Solidworks programında analiz yapılarak borulara etki eden gazın basınç kayb1 ve 1sı transferi tespit edilmiştir. Tespit sonucunda deneysel verilerle kıyaslama yapılarak en uygun fin aralığı belirlenmiştir. Ekonomizer performansına etki eden basınç kaybına göre deneysel çalışma ile kıyaslaması sonucunda $5 \mathrm{~mm}$ kanat aralığı uygun görülmüştür. Yapılan bu çalışmadaki 1sı değiştiricilerin farklı tasarım koşullarında modellemesi de diğer çalışmalara ilave olarak bir bilgi kaynağı oluşturacaktır.

\section{Teșekkür}

$\mathrm{Bu}$ çalışmanın gerçekleştirilmesinde, değerli bilgilerini bizlerle payşalaşan saygıdeğer çalışma arkadaşlarımız Gökhan CENGİZ ve Eren BAĞLAN'a sonsuz teşekkürlerimizi sunarız.

\section{Kaynakça}

Bozkula, G. (2016). Kendinden Kanatlı (Finli) ve Türbülatörlü Turbo Fin Boru Sisteminin Geliştirilmesi (Master's thesis, Namık Kemal Üniversitesi).

Çıtır H. (2013).Endüstriyel tav firınında ekonomizer tasarımı Energy productivity effect of economizer in reheating furnaces. (Master's thesis, Karabük Üniversitesi.)

Demir, K. C. (2017). Baca gazının ekonomizere giriş ve çıkış tasarımının 1S1 geri kazanımına etkisinin incelenmesi (Master's thesis, Namık Kemal Üniversitesi).

Hamzaoğlu (2019). Ramöz Makineleri Verim Arttırma Yöntemleri ve Ekonomizer Uygulaması (Master's thesis, Trakya Üniversitesi).

Karataş T. (2019). CFD analysis of shell and tube heat exchanger. (Master's thesis, İnönü Üniversitesi)

Kocabaş, C. (2014). Farklı malzemelerden imal edilmiş plakalı 1Sı değiştiricilerinin atık 1sı geri kazanım performanslarının deneysel analizi (Master's thesis, Fen Bilimleri Enstitüsü, Bilecik Şeyh Edebali Üniversitesi).

Özağdaş, E. (2020). Bölgesel 1sıtma sisteminde ekonomizer tasarımı ile enerji geri kazanım potansiyelinin araştırılması (Master's thesis, Fen Bilimleri Enstitüsü, Kafkas Üniversitesi).

Savaş, A. F., \& Kocabaş, C. (2019). Endüstriyel Kazanlarda Yanma Veriminin Süreç Geliştirme Teknikleri Kullanılarak İyileştirilmesi. Bilecik Şeyh Edebali Üniversitesi Fen Bilimleri Dergisi, 6(2), 357-368. 
Tekin (2006). Sivıdan Sivıya Gövde-Boru Tipi Is1 Değiştiricilerinin Bilgisayar Destekli Tasarımı (Master's thesis, Ege Üniversitesi).

Tokgöz, N., \& Özgün, Ö. (2019). Atık Is1 Geri Kazanım Sistemlerine Yönelik Literatür Araştırması ve Sanayiden Örnek Vaka İncelemesi. Çukurova Üniversitesi Mühendislik-Mimarlık Fakültesi Dergisi, 34(2), 57-72.

Uysal, H. L. (2019). Endüstriyel boyahane tesislerinde baca gazı atık 1sısının geri kazanım analizi ve bir uygulama (Master's thesis, Balıkesir Üniversitesi Fen Bilimleri Enstitüsü).

Yeşil, Ç. (2012) Ekonomizerler ve Düşük Sıcaklık Korozyonu. Tesisat Dergisi, 199, 54-60 